\title{
CHRONIC ALCOHOLISM AND REPRODUCTION.
}

\author{
BY THEODORE NEILD, M.A.
}

THE researches of Dr. Bertholet, of Lausanne, into the effect of chronic alcoholism upon the reproductive glands and upon other organs, deserve to be better known in this country. They are extensive, appear scientific and accurate, and are remarkable in their findings. They are important in themselves, and also should stimulate similar work in this country where "control" material. still more than morbid, is so much more plentiful than in Switzerland. The immediate occasion for reference to these researches is the recent publication* of a review of Dr. Bertholet's 1913 memoir, by Dr. R. Wlassak, of Rome. Dr. Wlassak is known as one of the most scientific of the medical men who deal with the temperance question, and the present writer feels that it will be best simply to translate the review in question. $\uparrow$

It was to the London International Temperance Congress, in 1909 , that Dr. Bertholet first sent a communication upon the alteration of testicular tissue in chronic drinkers. A little later A. Weichselbaum published a research which agreed essentially

* See May issue of the Internationale Monatsschrift, pp. 156-162.

+ For full particulars regarding Dr. Bertholet's researches, see the following: “De l'Influence de l'Alcoolisme chronique sur le Testicule humain" (Communication préliminaire), by Dr. Ed. Bertholet, Lausanne, Proceedings of the International Congress on Alcoholism, London, 1909, pp. 294-298; "Altérations anatomo-pathologiques, observées à l'Autopsie de 100 Alcooliques chroniques," by Dr. E. Bertholet, Proceedings of the International Congress on Alcoholism, The Hague, 1911, pp. 181-186; "Action de 1'Alcoolisme chronique sur les Organes de l'Homme, et sur les Glandes reproductrices en particulier," by Dr. Ed. Bertholet, Lausanne, 1913 ; E. Bertholet's "Researches on the Effects of Chronic Alcoholism," review, by Dr. R. Wlassak.

VOL. XII. 
with Bertholet's findings. Till then, all which was known was that Simmond's researches showed that in drinkers the seminal vesicles often lacked spermatozoa. Neither Bertholet's work nor Weichselbaum's covered a very great number of cases. Fresh research, upon a greater range of material, was most desirable, as only a research upon other influences which act in a manner somewhat similar to alcoholism-such as chronic disease, age, etc. -could throw light on the subject.

A new, most accurate, and comprehensive research by Dr. Bertholet has essayed to fill this lack as far as was possible. His material includes 163 cases of " drinkers," and 100 cases of " nondrinkers." In every case information was collected as to the use of alcohol. In the group of "drinkers," Bertholet set down everyone who was known to have a daily consumption of more than 100 c.c. of pure alcohol--more, that is, than $1 \frac{1}{2}$ litres of wine, or 2 litres of beer; and he set down among the "non-drinkers" all who did not exceed this limit.* All such classification is affected by inaccuracies, and is arbitrary. It is self-evident, as Bertholet rightly remarks, that this distribution can tell against the "non-drinker" alone, among whom a few "drinkers" may be found. The most important finding of the investigation is that testicular degeneration is by far the most frequent alteration which the bodies of inebriates show. Bertholet found it in 86 per cent. of the alcoholic section. Changes of cardiac muscle were found in 70 per cent.; atrophy, or enlargement, of the kidneys was found in 64 per cent.; atrophy, or enlargement, of the liver in 59 per cent.; gastric affection in 45 per cent.; tuberculosis in 32 per cent.; pulmonary affection in 23 per cent.; and sanguineous inflammation of the dura mater in 9 per cent. of the cases. But these figures do not assume their full importance until we compare them with those of the " non-drinker" section. Comparison, moreover, is rendered rather difficult through the dissimilarity of ages in the two sections. In the " non-drinker" section we find proportionately more elderly persons. Only 12 per cent. of the alcoholics were over 60 ; there were 28 per cent. among the "non-drinkers." As testicular changes become more frequent as age advances-as do the other affections of the organs which were noted (with the exception of tuberculosis)-

* Equal to $3 \frac{1}{2}$ ounces. Even Laitinen's "moderate drinker" took only one glass (the glass Professor Laitinen showed the present writer as the usual size was smaller than the English glass) of beer of 4 per cent. alcoholic strength per diem.--T. $N$. 
the above fact tells against the "non-drinkers." In spite of this, the differences are very considerable. Testicular affections are set down to 86 per cent. of the "drinkers," against 29 per cent. to the " non-drinkers." There is also a great difference in kidney affections -64 per cent. among the "drinkers," and 16 per cent. among the " non-drinkers."

Tuberculosis alone constitutes an exception : Bertholet found 32 per cent. among the "drinkers," and 33 per cent. among the " non-drinkers." But this fact justifies no further deductions. For Bertholet tells us that, at the outset, he excluded tuberculous drinkers from his research, because he was of opinion-a view relinquished later-that tuberculosis always brought on testicular degeneracy. Consequently, of course, cases of tuberculosis were excluded from the "drinker" section, and in this particular the material was not strictly comparable. Whether this source of error is sufficient to explain the almost equal number of tuberculous persons among the "drinkers" and " non-drinkers" must remain an open question. The connection between alcoholism and tuberculosis appears to be very complex.

Bertholet has subjected testicular changes to an extremely accurate microscopic examination. He divides his anatomical findings into four groups. The most advanced stage of alteration is recognized by complete shrinkage of the gland-cells, and entire absence of spermatozoa. In Group 2, the gland-tissue is much altered, the connective tissue is partly degenerate and partly proliferous, whilst spermatozoa are still found, but in small number. In Group 3, Bertholet places a state showing a slight alteration of the tissues of the glands and of the connective tissues, and the presence of more spermatozoa. Finally, Group 4 comprises the perfectly normal condition. Some well-designed plates aid the reader to differentiate the groups. In each of the groups separately Bertholet has carried out the numerical comparison between the series of "drinkers" and " non-drinkers." He finds complete degeneracy of the testicles in 55 per cent. of the "drinkers" and in 15 per cent. of the "non-drinkers"; degeneracy. as shown by the existence of few spermatozoa in 31 per cent. of the "drinkers" and in 14 per cent. of the "non-drinkers." Initial organic changes were found in 12 per cent. of the "drinkers" and in 32 per cent. of the "non-drinkers." A fully normal state was found in 2 per cent. of the "drinkers" (!) and in 40 per cent. of the "non-drinkers." It is at once observed how the numerical proportion changes from Group 2 on. And this is 
still more self-evident if we combine Groups 1 and 2 on the one hand, and Groups 3 and 4 on the other. We then see that the testicular tissue is greatly altered in 86 per cent. of the "drinkers" and in 29 per cent. of the "non-drinkers"; whilst the "drinkers" show a more or less normal state of that tissue in 14 per cent. and the " non-drinkers" in 71 per cent. of the cases.

[Bertholet has also made the above comparison between the four groups, dividing the material up in parallel quinquennia; this, aided by diagrams, gives striking results, but in some quinquennia, at least, the individuals are too few to give trustworthy comparisons. - T. N.]

Bertholet has devoted another separate classification to show the distribution of testicular degeneration among the different diseases which caused death. Groups 1 and 2 are taken together. Among the alcoholic no distinct connection stands out between testicular affections and the fatal illness, except in the case of malignant tumours, which without exception showed damage to testicular tissue. Other figures vary between 93 per cent. and 84 per cent. The differences in the case of "non-drinkers" are greater. Here the most striking figure is that of the tuberculous: 48 per cent. of these show more markedly degenerated testicular tissue. Very significant is the comparison in the case of deaths from accident, suicide, or as the result of operations. The two groups contain respectively 23 and 21 cases, and the average age is nearly the same in both, consequently comparison is here entirely permissible. In the "non-drinker" group Bertholet now found not a single case of the more marked testicular change, whilst there were 69 per cent. in the "drinker" group! This contrast constitutes one of the most convincing facts of the whole research. The further numerical analysis which Bertholet works out on this lends additional strength to this impression.

With part of his material (81 "drinkers" and 58 " nondrinkers") Bertholet subjected the testicular tissue to a microscopic examination as to the presence of fat. Healthy testicular tissue always contains small quantities of substances which give the usual fat-reactions; unusually abundant quantities of fat alone are of pathological significance. Bertholet's comparison of the two groups, conducted with great care and accuracy, gives in general the same differences as did the examination of the cellular structure of the testicular tissue, namely, a considerably larger number of cases with more marked accumulation of fat among 


\section{The British Journal of Inebriety}

the "drinkers." It was, however, here seen that among the "non-drinkers" over 45 years also, there was, without exception a more marked fatty accumulation of the testicular tissue. But the difference only comes out in its full distinctness if those individuals alone are compared who have not reached 45. Then we get a fully normal condition in 34 per cent. of the " nondrinkers," whilst among the "drinkers," on the other hand, it was 2 per cent.

[In an appendix Bertholet gives a similar research upon the ovaries of a few drinking women. Here, too, he found atrophy of the germ-tissue; but the cases, as Bertholet says, were too few to generalize upon.-T. N.]

What do we gather from this array of facts touching the influence of chronic alcoholism upon the germ-glands? Let us go over the most important points that have been established. It has been seen that in "drinkers" it is the testicular tissue which is the most frequently damaged. If we disregard the less important injuries, only 14 per cent. are found to be unharmed; and fully normal testicular tissue is found in only 2 per cent. of the " drinkers." The injury of the testicle in "drinkers" shows no apparent connection with the immediate cause of death. Even "drinkers" whose death is caused by external violence show degenerate sperm tissue to the extent of 69 per cent. It must be noted also that Bertholet has succeeded in producing testicular change in animals with alcohol. (He intends to publish a detailed communication on this subject.) A recently published research, conducted in Weichselbaum's Institute by J. Kyrle and K. J.Schopper, * gives the same result. Putting all these things together it cannot be doubted that chronic alcoholism has a causal connection with testicular degeneration. Recourse must be had to the most ingenious assumptions to avoid this conclusion. And that these testicular changes, taken together with the degenerate offspring of drinkers, support Forel's blastophthoria is equally certain.

A second question, which must be answered with more care, is this, whether alcoholism is the only cause of the damage to the germ-glands observed in drinkers. In this connection it must not be forgotten that Bertholet found more or less testicular change even among his " non-drinkers," to the extent of 29 per cent. of

* "Untersuchungen über den Einfluss des Alcohols auf Leber und Hoden des Kaninchens" (Wiener Klinische Wochenschrift, 1913, No. 51, p. 2101 et seq.). 
the cases, and these even among those in the earlier stages of life. Especially important seems to me the fact that in the group of "non-drinkers" a clear connection is seen with the disease that caused death. In the case of those dying from tuberculosis, the number of those in whom the germ-glands were damaged rises to 48 per cent.; the figures are lower in those dying from other fatal illnesses. The last word has not been spoken as to the interpretation to be placed on this. Bertholet draws attention to the fact that among his tuberculous individuals there are many children of drunkards. It is, of course, conceivable that this factor both increases the liability to infection from tubercular germs, and also lowers the resistivity of testicular tissue to various influences, including possibly the toxin of tuberculosis. Let us not forget von Bunge's statistics as to tuberculosis in the descendants of drinkers. There are, however, other possible interpretations; and for the present we have only hypotheses before us. However this may be, Bertholet can claim much credit for having proved the frequency of testicular degeneracy. For all future researches on heredity and constitution, this is a fact of great and wide significance.

Generally speaking, we must often gather from the figures as to "non-drinkers" that the resistivity of the germ-tissue varies much with the individual, therefore some predispositional factor enters in. In treating of the effect of alcoholism we must reckon with this factor as much as when treating of other causes of death. How various, to take a single example, are the effects of syphilitic infection, from case to case, in their course and localization. The syphilitic alone suffers from creeping paralysis, but in only a trifling percentage of those in our lands who are infected does this ending follow. There is therefore a certain predisposition to paralysis, the character of which is unknown. Similar instances exist in abundance; there is therefore nothing surprising if the individual organism makesitself felt also in the case of the effects of alcohol. It must be the task of further research to determine how far a predisposition to testicular degeneracy exists, and whether possibly it coincides with the nervous predisposition to drunkenness. We must, however, point out that these theoretical questions do not affect the immense practical significance of these findings of Bertholet's. No one has objected to the movement against the spread of syphilis that the worst form this disease takes is a result of the predisposition of the person concerned! 


\section{The British Journal of Inebriety}

Bertholet expresses the wish that others will undertake similar research. Let us hope his wish may be gratified, and wherever possible in a land where the "control" material can consist of life-long abstainers. We cannot be sufficiently grateful to Bertholet for the vast amount of laborious and engrossing special researches which he has devoted to his subject. Nevertheless, it must be admitted that, in some of his numerical analyses, his material is so small that we cannot help wishing for a repeat research upon a much wider basis. A single person's work could hardly compass such a research; only a pathological institute, which investigates and collects the cases as Bertholet has done, can carry it through.

[The last two pages of the above review deal with a different subject. - T. N.] 